\title{
Femtogram per Milliliter per Milligram per Kilogram per Day
}

National Cancer Institute

\section{Source}

National Cancer Institute. Femtogram per Milliliter per Milligram per Kilogram per Day. NCl Thesaurus. Code C119339.

A unit of concentration equal to femtogram per milliliter, divided by milligrams per kilogram per day. 